\title{
CHALLENGES AND \\ SOLUTIONS IN \\ ETHNOGRAPHIC \\ RESEARCH
}

Ethnography with a Twist

Edited by Tuuli Lähdesmäki,

Eerika Koskinen-Koivisto, Viktorija L.A. Čeginskas and Aino-Kaisa Koistinen

First published 2019

ISBN: 978-0-367-37688-8 (hbk)

ISBN: 978-0-367-37685-7 (pbk)

ISBN: 978-0-429-35560-8 (ebk)

\section{CHAPTER 1}

\section{POLY-SPACE}

CREATING NEW CONCEPTS THROUGH REFLEXIVE TEAM ETHNOGRAPHY

Johanna Turunen, Viktorija L. A. Čeginskas, Sigrid KaasikKrogerus, Tuuli Lähdesmäki and Katja Mäkinen

(CC-BY-NC-ND 4.0)

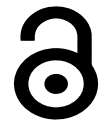

Routledge 


\title{
POLY-SPACE
}

\section{Creating new concepts through reflexive team ethnography}

\author{
Johanna Turunen, Viktorija L. A. Čeginskas, Sigrid Kaasik- \\ Krogerus, Tuuli Lähdesmäki and Katja Mäkinen
}

\section{Introduction}

Ethnographic research always contains an element of surprise (Malkki 2007). In this chapter, we engage with a process of knowledge production and collaborative sense-making that grew out of such unexpected elements. At the core of this chapter are the short "bizarre" moments that the EUROHERIT" research team felt when conducting ethnographic fieldwork at selected heritage sites that the European Union (EU) has awarded with the European Heritage Label. These "bizarre" moments occurred to us unexpectedly and outside our planned observation agenda, when our attention shifted to some secondary or minor details or trivial events, which suddenly became very meaningful for understanding the world(s), people and life entangled with the heritage site.

Although usually lasting only a short time, between a flash of surprise and a short discussion, these moments often had continuing effects throughout the remainder of the fieldwork. When viewed separately, the moments seemed deeply personal and disconnected. It was only in retrospect, when viewing them jointly, that we came to perceive their importance for understanding something new about heritage sites and the idea of heritage itself. As we have come to realize, these experiences and the insights they brought about may change the ways in which we relate to heritage and perceive its meanings.

To better grasp these experiences, we propose that heritage sites can be approached as poly-space in the sense that they enable and contain different spatial, temporal, affective, sensory and cognitive experiences in one physical place, the heritage site. Poly-space includes four distinct aspects that are in continuous flux, processual and interrelated: 1) an element of suddenness and surprise, 2) experience of bizarreness, 3) social agency and interaction and (4) affect, emotion and empathy. The concept of poly-space encourages (self-)reflection and enables discussion 
of the various temporal and spatial dimensions included both in the heritage narratives and practices and in individual experiences felt at the heritage site (for a more detailed definition, see Lähdesmäki et al. 2020).

In this chapter, we outline how we developed the concept of poly-space by discussing our fieldwork experiences and making sense of them through the process of "interpretive reflexivity" (Lichterman 2015) and affective sharing. Approaching methodology through the lens of knowledge co-creation, according to Boyer and Marcus $(2015,3)$, can be considered as an enabler of epistemological critique. Poly-space can be used to re-evaluate the depth of ethnographic knowledge even when the duration of fieldwork is not long: affective, unconscious experiences inspire, trigger and entangle with interpretive and cognitive processes, to mutually create new insights and knowledges. As Dalsgaard and Nielsen $(2013,3)$ note, "the length of the fieldwork period has constituted a central albeit much contested factor for determining the quality of collected ethnographic data". Spending months or years in the field has become problematic due to the fast pace of academic research today; emphasizing duration is ill-suited for mobile and team-based ethnographic approaches. Extensive fieldwork periods are connected with the "chances of serendipitous findings or surprises, which will supposedly destabilize the researcher's prior understandings and generate new insights" (ibid.). However, we argue, emphasis on duration can be (partially) remedied by enabling ethnographers "to take often marginalized forms of embodied affective, imaginative and creative knowledge seriously" (Culhane 2017, 7), which allows us to challenge how we come to know the things we know.

Although we mainly engage here with the theory and methodology behind our collaborative work and conceptual innovation, a short introduction to our fieldwork is needed before we enter these debates. The European Heritage Label (EHL) is the EU's heritage action initiated in 2011 to highlight the so-called European significance (see Lähdesmäki and Mäkinen 2019; Turunen 2019) of heritage sites across Europe. Creating an idea of joint European cultural heritage is fundamentally a political act. The EUROHERIT researchers are most interested in this political nature of the production of ideas and practices of "European heritage" and its identity-political relevance. To access these politics, discourses and practices of heritage, the EUROHERIT team conducted ethnographic fieldwork at 11 EHL sites ${ }^{2}$ and at the European Commission in Brussels in 2017 and 2018. The duration of each visit ranged between four and six days. All researchers participated in the data collection. The fieldwork at each site was primarily carried out by one researcher, although some sites were visited by several members of the project, either before or after the actual fieldwork. Nativespeaking research assistants were used at some of the sites, especially for the visitor interviews.

During the fieldwork, we collected a broad range of data both on and off the site through participant observation, interviewing and going through documentary, archival and academic literature (e.g. Clifford and Marcus 1986; Culhane 2017). This data includes extensive interviews with both heritage practitioners and visitors 
to the sites, as well as the use of a broad range of visual and written materials related to the sites and their exhibitions. Our analysis of different aspects of this data has been published elsewhere (e.g. Lähdesmäki et al. 2019; Lähdesmäki et al. 2020). In this chapter, we focus on material produced by the team members during and after the fieldwork. These include fieldwork memos and journals, notes from project meetings, email exchanges and informal conversations. These different forms of communication between the project researchers form the core empirical data used here to decipher the dynamics of collaborative knowledge creation and collective sense-making practices.

\section{Towards collaborative ethnography and collective interpretive reflexivity}

Ethnographic research has evolved from its roots in cultural anthropology and the colonial entanglements that the discipline had in its early forms (e.g. Stocking 1991; Comaroff and Comaroff 1992). This overcoming of historical legacies has not been an easy or simple process. As the vast literature on ethnographic research methodologies shows, the practice and ethics of ethnographic research has gone through several cycles of reinterpretation. It has come a long way from classic anthropological ethnographies, often conducted in colonial settings (e.g. Malinowski 1922/1972; Evans-Pritchard 1940) or the early works of scholars of the Chicago School of Sociology, who used ethnographic approaches to study cultures of disenfranchised minority groups in urban environments (e.g. Park, Burgess, and McKenzie 1926; Blumer 1933). Influenced by the reflexive turn and increasing postcolonial critique of the 1980s (e.g. Geertz 1973; Clifford and Marcus 1986) ethnography has developed into a widespread approach that endorses reflexivity and co-production of knowledge as the crucial elements of research practice and analysis. The steady flow of literature on the relationships between fieldwork practices, methodology and theory (e.g. Cerwonka and Malkki 2007; Puddephatt et al. 2009; Burgess and Murcott 2014), the social nature of ethnographic knowledge (e.g. Katz 2012), ethnographic writing (e.g. van Maanen 2011), reflexivity (e.g. Davies 2008) and new alternative and multifaceted approaches to ethnography (Hämeenaho and Koskinen-Koivisto 2014; Elliott and Culhane 2017), all show that the development of ethnographic practices is ongoing. In this process, the role of interdisciplinary knowledge production, intersectional social positions and new arenas of ethnographic research, such as online environments, are emerging areas of debate.

Moreover, in recent years, there has been a shift towards collaborative team ethnographies (e.g. Spiller et al. 2015), multi-sited approaches (e.g. Marcus 1995; Falzon 2009) and mobile ethnographies (e.g. Jarzabkowski et al. 2015). This multisitedness has arisen from changing cultural mobilities that have "transformed locations of cultural production" (Marcus 1995, 97) forcing ethnographers to focus on connections or associations between separate places, rather than on a single site or entity. These mobile research approaches (see also Büscher and Urry 2009) aim to 
trace or follow their ethnographic object through multiple locales. The aim of multi-sited approaches is not to produce "thick descriptions" (Geertz 1973) of single sites or precise cultural practice, but rather to engage with complex transnational cultural phenomenon that "cannot be accounted for by focusing on a single site" (Falzon 2009, 1).

This mobility, scale and transnational nature of contemporary cultural transformation has increasingly led researchers to adopt collaborative approaches to both data collection and analysis (e.g. Jarzabkowski et al. 2015). This was also the case in our research process. Tracking and analysing transnational production of the ideas and practices of "European cultural heritage" not only involves numerous research locales and layers of meaning but also requires multiple sets of expertise. The team was able to bring together a broad range of disciplinary backgrounds in the social sciences and humanities, as well as several nationalities and languages. Although most of us had collected data by ethnographic means in previous research, only one of us readily identified herself as an ethnographer. Participating in a reflexive, collaborative ethnography as a form of knowledge production was therefore a new experience for most of us.

The process of bringing different disciplinary viewpoints into a coherent approach has been described in many ways. Franks and colleagues (2007) have characterized this process as "knowledge integration", whereas Spiller and colleagues $(2015,558)$ have settled on the use of carnival as an allegory for a "transformation, in which the world is turned upside down". As they argue, this space, that is akin to Bakhtin's "place-beyond-place", creates the openness to let go of our disciplinary boundaries and to think again through new perspectives. Moreover, there is an element of serendipity (e.g. Rivoal and Salazar 2013; Hazan and Hertzog 2011) involved in the process of creating new knowledge. This serendipity allows us to relax our conceptions of knowledge, facilitating the emergence of new forms of knowledge out of the combination of different disciplinary backgrounds and our own affective experiences. By affective experiences, we refer here to emotional reactions, sensory experiences, gut feelings and other embodied sensations we experienced during our fieldwork. All knowledge constructed through such experiences challenges the conventional Cartesian division of mind and body and enables us to "articulate a realm of experience, thinking and being; one that has formerly been considered as inarticulatable" (Tolia-Kelly, Waterton and Watson 2017, 1). By making inarticulatable knowledge articulable, we acknowledge the subjectivity and plurality of the knowledges that surround us. They overlap, entangle and build in relation to other forms of making sense of the world, and testify against ideas of universal truth or knowledge.

As it is often stated, all knowledge gained through ethnography is, in many senses, partial (Clifford 1986), situated (Haraway 1991) and plural (e.g. Fenske and Davidovic-Walther 2010). Acknowledging this incompleteness highlights our own limitations as ethnographers and producers of knowledge. Focusing on the "inarticulatable" in team ethnography, however, means that our collective embodied knowledges include hidden, silent and tacit observations of multiple 
researchers that exist rather in terms of affects, interpretive insights and shards of wisdom than in a form of easily sharable knowledge. Then the main question, brilliantly framed by Jarzabkowski, Bednarek, and Cabantous $(2015,7)$, is "how [do] we make such ethnographies 'whole' given that the ethnographic experience of 'being there' is said to be intrinsically personal"? In other words, how can we share the (embodied) experiences and insights of being there when we have each conducted our fieldwork alone? The "whole" in this context does not relate to definite, true knowledge, but to the collective sum of our subjective observations, their internal relations and what they tell us about our subject - European cultural heritage.

To understand our experiences and allow affective knowledge to emerge, we needed to think beyond our positionalities as academics relating to our research subjects (see Bourdieu and Wacquant 1992) and to practice active reflexivity in terms of our positionalities within the team. As Creese and colleagues state, building on the work of Jones and his co-authors (2000), the team dynamic of ethnographic research requires the "interpretive knowledge building exercise to be explicitly interactive and negotiated" (Creese et al. 2008, 200). This negotiation is formed through the "interaction of different identities/values/histories that are brought directly into the research process by different team members" (ibid.). For us, negotiation of viewpoints within the team has been a continuous process. Although there are many similarities between the team members - all of us are white, able-bodied, European women with higher education and a certain level of privilege - we are also different in terms of our nationalities, cultural backgrounds, family status, mother tongues and language skills, disciplinary identities, areas of interest and more. Balancing these intersectional differences and deciphering their many influences on our dynamics of knowledge production is not easy; for example, notions of class status differ in our respective native countries and many of these differences have both historical roots and contemporary manifestations. Moreover, all of us (on the team and in general) have different affective capacities and registers (Tolia-Kelly 2006, 213) which actively influence the way we perceive and interpret our surroundings. For Tolia-Kelly, discussing affective capacities is a way to promote a "non-universalistic understanding of emotional registers" (216). This highlights how individuals not only perceive affective geographies differently due to intersectional dynamics of social positioning and associated power hierarchies (see also Haraway 1991), but also respond and react differently to affects. Although not always actively acknowledged, all these aspects were entangled in every phase of planning and conducting our joint ethnographic fieldwork.

We have attempted to counteract this disjointedness of ethnographic knowledge that has resulted from a collaborative approach, by practising what Lichterman (2015) has conceptualized as "interpretive reflexivity", a process of not only figuring out our own positionalities but trying to understand "how we came up with our interpretations" (ibid., 38). As we embarked on this reflexive process together, we needed to figure out our roles as co-producers of knowledge and 
how we collectively come to know "something". This practice has a direct impact on the more epistemological conditions that influence our knowledge production and the way we know what we know as individual ethnographers and as a team. By practising interpretive reflexivity, it is possible to "show how we came up with the patterns we call meaningful or cultural" (ibid., 42), and more importantly, as we will show, to create knowledge that is beyond the scope of a single ethnographer.

\section{Practices of sharing knowledge}

There are different modes of sharing in ethnographic teamwork (e.g. Jarzabkowski et al. 2015, 19). These sharing practices can be conducted face-to-face or via virtual tools and at different stages of research, whether before, during or after fieldwork. Our collaboration entailed multiple forms of sharing, including sharing the entire data with all team members, analysing data together, cross-commenting on academic articles and co-authoring a book based on our fieldwork (Lähdesmäki et al. 2020). In this chapter, we focus on the relationship between emotional and empirical sharing as a form of conceptual development. Through practising interpretive reflexivity, we analyse how different processes of sharing emotions, experiences, ideas and insights enabled new forms of knowledge to emerge and how these were used to develop the concept of poly-space.

We used various tools to communicate in our team. Face-to-face meetings are crucial for sharing experiences but since we neither live nor work close to each other, the use of virtual tools was key to our cooperation. We used Skype video conference calls, collaborative writing on virtual platforms and chat platforms, Whatsapp group messages and a lot of email exchanges. Many emails focused on the practical aspects of teamwork, but early on, these emails also contained "emotional labour". By sharing anecdotes from the conferences, fieldwork experiences and frustrations of academic work, the team members settled into their own sharing habits. Some focused mainly on meetings in person, whereas others shared more online. For example, Johanna and Sigrid accidentally found themselves sharing long, meandering emails, resembling free writing or a stream of consciousness, which allowed them to go through their emotions, but also work on unfinished thoughts and emerging ideas in a pressure-free environment. Viktorija and Katja worked a lot through discussions on Skype, while Viktorija and Sigrid found conversations and emails in their Estonian mother tongue a more natural way to make sense of their ideas and experiences.

These multiple ways of sharing constructed what Wasser and Bresler $(1996,6)$ have conceptualized as a "[p]owerful interpretative zone". For them, multidisciplinary teams create an affective space "where multiple viewpoints are held in dynamic tension as [the] group seeks to make sense of fieldwork issues and meaning" (ibid.). Crossing the boundaries of one's own discipline and knowledge is crucial. Within our team these multidisciplinary tensions not only started to dynamically provoke our thinking, but also helped to entangle our disciplinary and 
cultural knowledges into new forms of conceptualizing the realities and imaginaries embedded in our vast research data.

Emails between members of the research group were a crucial tool in coping with the fieldwork and the many emotional reactions it sparked in us. Viktorija, as the first to go into the field, started this tradition but sharing experiences from the field became a habit for the rest of the team as well. For example, Johanna, the most junior member of the team who had very limited experience of ethnographic fieldwork, wrote a long email after her first day of the field in Camp Westerbork, the Netherlands, a former transit camp for Jews, Roma and Sinti during the Second World War.

\section{From: Turunen, Johanna}

\section{Sent: 27 January 2018 7:08 PM}

To: Čeginskas, Viktorija; Lähdesmäki, Tuuli; Mäkinen, Katja; Kaasik-Krogerus, Sigrid

Subject: So this is field work?

Hi all and greetings from Westerbork.

Day one is done and although as an eternal internal critic there were some things I should have done better (I think I rushed too much in the interviews), I think overall, we already got more than we bargained for and even though I had a really nice day I am not sure I was truly prepared for all of this. I almost cried in one of the interviews ... but I will get back to that.

Johanna goes on to give a long and detailed record of her observations at the site, as well as a summary of a very touching interview with one of the visitors - a person who had lost almost his entire family during Holocaust. In her email, Johanna also recounts a second chance encounter, which in fact came to characterize her stay in Camp Westerbork and evolved in her field journals into a key element of her experience of poly-space at this site, although she did not have words or concepts to describe it as such at this point. This was an encounter with another phase of the camp's history. For approximately 20 years, it served as a resettlement camp for a group of Moluccan refugees. As she continues in the same email:

Already in the morning, it turned out that our cab driver had been born at the camp. His parents had arrived there as refugees after the end of the Dutch colonial rule and he had lived the first 11 years of his life there at the camp. He talked of how he feels really torn when going there. For him it was a happy place. He was happy as a child. Playing in the forests. No-one in the community told the children what the place had initially been used for. He only found out much later when he was older.

This email sparked words of encouragement but also interesting reflections from the team members. After the fieldwork, Johanna recounted the effects of the 
experience with the Moluccan taxi driver once more in her notes. This time she put her experience into the perspective of her whole research stay. The excerpt brings out the powerful impact that this early encounter had and the time-bending effect it seemed to produce.

Later when walking in the museums, the forest and around the now demolished camp and reading and hearing the heartbreaking personal stories of the people who had passed through it, in the back of my mind I kept hearing laughter. It was the laughter of the Moluccan children whose families had been forced out

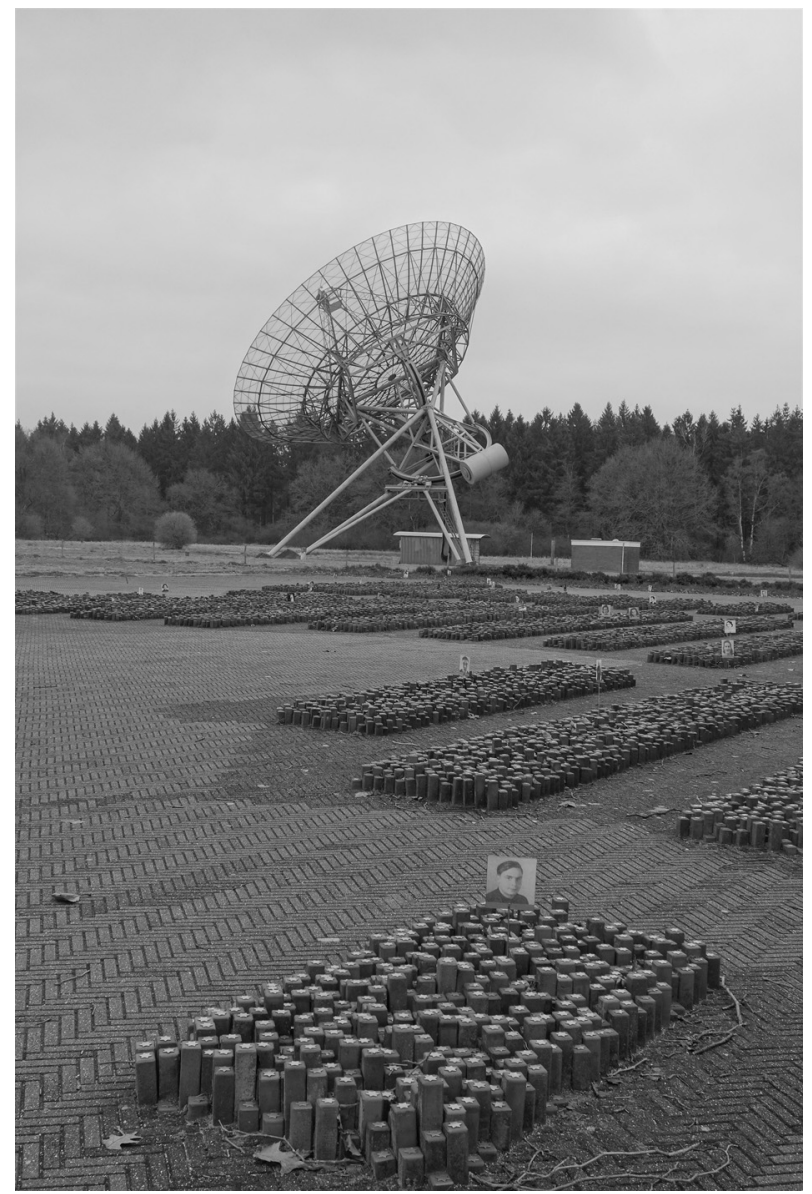

FIGURE 1.1 Part of the forest around the former campground in Camp Westerbork has been cleared for a field of radio telescopes. These telescopes, placed next to the memorial to the camp's victims, are visible from the site of the former camp, contributing to the bizarre experience of different worlds meeting. Copyright: EUROHERIT 
of their home in Indonesia, but who managed to turn the transit camp into a happy home for themselves. Although the memories of the site were quite different for their parents who carried the trauma of leaving Indonesia and who knew the history of the place they were living in, the memories of the happy, innocent childhood lingered and almost haunted me throughout my visit. However, it was not a terrifying haunting, but a haunting of hope. A sign that even in the saddest of places, we can find happy memories.

Although the mixing layers of the Holocaust, the Moluccan child and the contemporary moment of the fieldwork already had some of the seeds of the idea of poly-space, this flux of temporalities was something Johanna initially felt to be just a silly trick of her mind and therefore she did not share this part of the experience with the team. Later on, as our team started to share stories and experiences more intensely, they started to become increasingly meaningful for us all and, through focusing on the small, the irrelevant and the banal, we were able to create space for new conceptual innovations.

\section{Constructing poly-space}

In spring 2017, when planning our fieldwork, we were seeking to investigate the multitemporality of heritage and the relationships between the past, present and future. Although this was a central interest of the project, it was only during and after the fieldwork in spring 2018 that the need for new concepts started to emerge. This quest for a conceptual tool that would allow us to make sense of our fieldwork experiences started as a theoretical one. We explored concepts like Foucault's (1997) "heterotopia", Turner's (1974) ideas on liminality and the liminoid, and Massey's (2005) work on "time-space compression". Next, we turned to memory and heritage studies and tried to think through Macdonald's (2013) "past presencing”, Rothberg's (2009) “multidirectional memory” and Hirsch's (2012) idea of "post-memory". While none of these seemed to fully capture our need, we looked outside the Western tradition of knowledge. Viktorija pondered on the idea of "time-knots" developed by Chakrabarty (2000) and Johanna read up on conceptualizations of time in Yoruba culture (e.g. Kazeem 2016).

While all this theoretical work was underway, we also turned inwards and started to look more into our own experiences. How did we experience time during our fieldwork? If and when temporalities mixed, what initiated that experience? The idea behind poly-space started to finally take shape after Viktorija shared her experience of one moment characterized by a sudden flux or overlapping of multiple layers of time and space, or a "flash of surprise". This happened in the Archaeological Park Carnuntum, Austria, an open-air reconstructed Roman site rebuilt using Roman techniques on the excavated remains of the original site.

I went alone to visit again the kitchen of the Villa Urbana. It was in the late afternoon and the late sun was shining into the otherwise rather dark kitchen. 
I surprised two small birds, which had flown in and were picking at bread. The bread is part of the fresh props lying in the reconstructed buildings with the intention to create an "authentic" experience of inhabited space and of travelling through time for the visitors. It then suddenly occurred to me that such situations had happened at precisely the same spot but some 1700 years ago, when birds flew into the kitchen to pick at food leftovers on the bare ground and were startled by the entrance of a slave, a servant, or the mistress of the house. This realization came as a surprise and made me feel closer to the situations that happened in the past. It helped me to reimagine or see the past with different "eyes", making it also part of a personal experience for me and imagining it as a personal experience for people unknown to me who had lived almost 2000 years ago. It made the otherwise still and material sites be filled with life and people.

When we started to think about poly-space through connecting it to some kind of external, interactive and affective catalysts - like Viktorija's birds or Johanna's taxi driver - we were able to see the relationships between our individual experiences as interrelated and embedded in the nature of heritage sites. While doing her fieldwork in the Great Guild Hall in Tallinn, Estonia, Sigrid had a sensation of the histories narrated in the museums entangling with contemporary realities beyond its doors. The permanent exhibition of the Great Guild Hall positions the Germans and Russians as both the main historical "Others" and as important past and contemporary minorities in Estonian society. The ambivalence of these historical and intercultural relations was mirrored in the social landscape that surrounded the museum - in a way expanding the narrative of the museum to the everyday practices of the old town of Tallinn. Sigrid, herself Estonian, explained this in her field journal.

On my very first fieldwork day, I experienced how this ambivalent relationship was performed there in the neighbourhood of the Great Guild Hall. On Wednesday afternoon, I heard shouts and noise from outside until the museum staff closed the large front door. I asked about this noise the next day during one of my interviews. It turned out that it was a protest in front of the Russian embassy [located just next to the museum], as my interviewee captured it, "against Russia, for Ukraine". This weekly protest is repeated every Wednesday afternoon, so according to the museum practitioner, it helps them to recall that, "oh, it is Wednesday again". This experience made me feel that the past, present and the future are indeed entangled and also very much "alive" and "in action" in heritage sites, sometimes in a rather surprising way.

This experience shows that the existing interaction with the social forces beyond the museum seemed to highlight and interlink continuities between the past and the present at the site, thereby creating a space where past and present coexisted in the same physical space of the museum and its immediate surroundings. In contrast, the fieldwork in the Franz Liszt Academy of Music in Budapest, Hungary, illustrated 
how the past and the present may exist in the same space but, as Tuuli notes, still be totally disconnected from each other.

I felt it was a big contrast to stand in Liszt's living room surrounded by his pianos, paintings of him made by famous Hungarian painters, marvellous old furniture, decorative wall paper, chandeliers and so forth, to listen to his music through an audio guide, and at the same time to look from the balcony window to the Vörösmarty utca metro station and see today's people walking and hanging around the metro station. For example, two black young men wearing trendy street clothes and headphones passed the windows while I looked out. They seemed to be so far from the reality of the room, although just some metres away. It felt that the past and today's world were there in this quarter at the same time, but without any connection to each other.

After coming up with these initial experiences, we started to see aspects of polyspace in our broader data. Going through the vast data we had collected, we often marked out issues related to poly-space and shared them with the team, as the next email from Sigrid demonstrates.

From: Kaasik-Krogerus, Sigrid

Sent: 11 January 2019 3:21 PM

To: Čeginskas, Viktorija; Lähdesmäki, Tuuli; Mäkinen, Katja; Turunen, Johanna

Subject: Some more poly-space

Dear all,

I started to go through the expert interviews and the data is very rich and inspiring indeed!

Although I try to focus on the centre-periphery aspect, I could not help other associations evoking while reading the interviews. I wrote down some ideas related to poly-space that may be relevant from the perspective of the article.

\section{Integrating senses and affects}

As more and more material related to poly-space emerged in our data, we started to pay more attention to the sensory and affective elements of our experiences with poly-space. It was clear that our insights were not gained by knowledge or cognitive work but through sensory experiences, emotional reactions and gut instincts - in other words, through our varied affective experiences. Our understanding of poly-space therefore encompasses an embodied element - the feeling of being swept out of time and place. Although often connected to the cognitive meaning-making practices around heritage, the sensorial and physical element of experiencing poly-space was crucial in terms of thinking heritage sites not only through poly-space, but also inherently as poly-space - as places where several histories and temporalities are layered and active. 


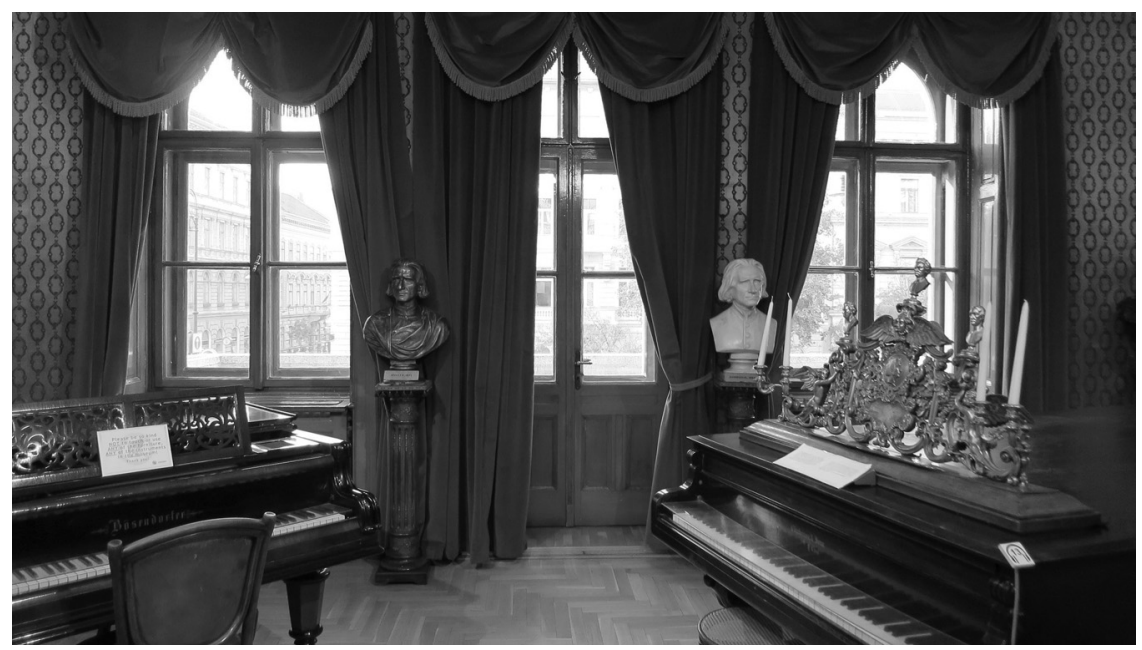

FIGURE 1.2 The view from the living room in the Franz Liszt Memorial Museum in Budapest. Copyright: EUROHERIT.

To include this affective, sensory experience in our elaboration of poly-space, our research draws from the affective turn in scholarship, which considers the body as a vehicle in creating "authentic" knowledge (e.g. Crang and Tolia-Kelly 2010; Waterton 2014). As Sather-Wagstaff (2017, 13) notes, "[a]ffective experiences translate into multiple effects, one being knowledge [...] and the other an excess residual that may never be fully categorized cognitively". There is a sociocultural, but also biological, aspect to these senses, which points towards the need to overcome the Cartesian separation of mind and body, or knowledge and feeling, in order to move towards an approach that celebrates and encompasses both aspects of our sense-making capabilities.

When debating the sensory experiences related to heritage, the visual aspects are often emphasized, because Western cultures tend to value sight as the highest of our senses. At times sensory experiences are more comprehensive, or to borrow from Sather-Wagstaff (2017), polysensory. This was the case in our fieldwork in Sagres Promontory, Portugal. Johanna described this in her field journal.

The most influential experience was the "Voice from the Sea" installation that was also known as the dragon's breath. It was a spiral shaped echo chamber built on top of the caves, which connect the promontory to the sea tens of metres below. In the chamber, you can stand on metal crates built on top of the cave entrance and feel "the dragon breathe". As the waves rush into the caves, a surge of warm air gushes through the caves and surrounds you with an explosive wind that shoots your hair up and roars around you. The bigger the wave, the louder the roar. Because of the rhythm of the waves, the gusts of wind come up and through the caves in a rhythm of someone breathing. 
The power was so intense that my research assistant had to leave. It all made her feel physically uneasy. I stayed behind and suddenly I was overwhelmed with the stories we had heard the day before from the staff. Stories of the promontory having been an ancient sacrificial site belonging to the gods and more importantly the story of Henry the Navigator, the Portuguese prince who had built his personal fortress on the Promontory. Henry's emblem was the black dragon and as I sat, listened and felt the dragon breathe around me, my mind travelled to the past, to people who came to the promontory, under the dark sky, with wooden torches in their hands to meet the dragon the fortress owner had locked up in the caves below.

This last excerpt from our field journals shows the complexity of the relationship between our sensory experience, the physical place of the heritage site and the narratives used to make sense of the many layers of history that the site encompasses. Ingold (2008) has explained how ethnographic research is about figuring out the "entangled relationships" between humans and non-humans and the natural, social and cultural environments that they inhabit. According to Ingold, these environments are not merely the "surroundings of the organism but a zone of entanglement" (ibid., 1797). Hence, poly-space became one way for us to make sense of the zone of entanglements that existed in and around the heritage sites we were researching. Our experiences and engagements all contained an element of memory, as they were in one or more ways embedded in our own past experiences, as well as the histories and narratives of the site. As such, it is easy to agree with Seremetakis (1994, 9, quoted in Sather-Wagstaff 2017 , 19) who states that memory "as a distinct meta-sense transports, bridges and crosses all the other senses". We do not want to claim that poly-space is an element

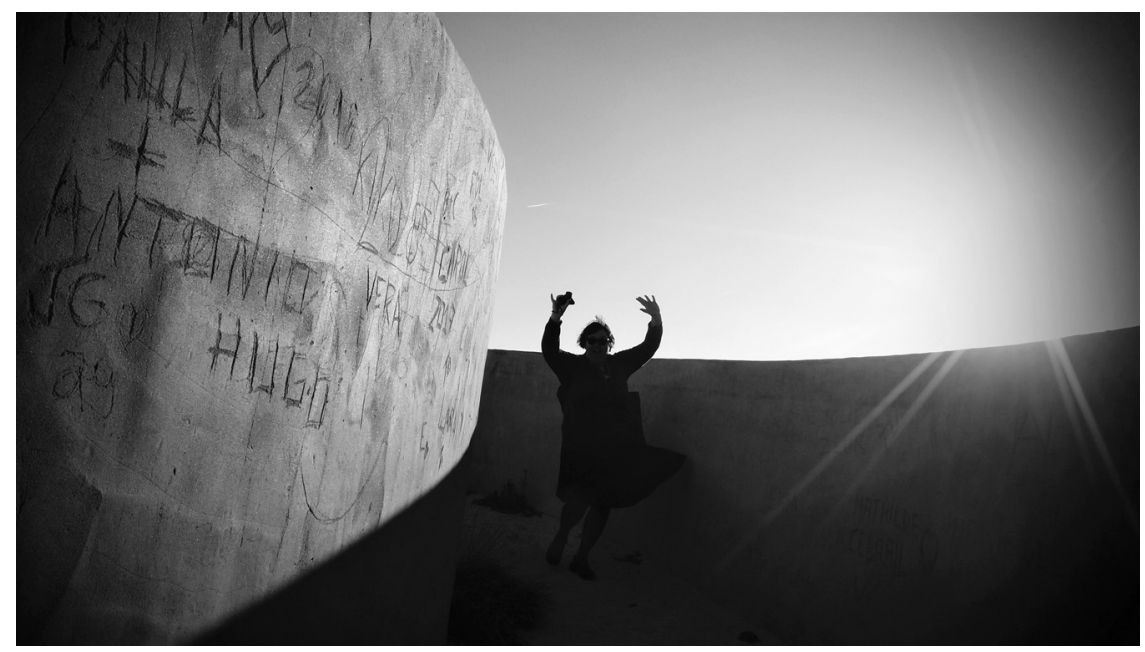

FIGURE 1.3 Johanna at the Voice from the Sea sound installation in Sagres Promontory Copyright: EUROHERIT. 
exclusively reserved for heritage sites. Rather, we see it as an experiential moment that can emerge in a multitude of surroundings. Nevertheless, the central role of memory in our meaning-making practices suggests that heritage sites as places that "materialize memory" are particularly active poly-spaces - physical places that make the entanglements of multiple moments and experiences of layered histories visible and tangible.

\section{Conclusions: how do we know what we know?}

There is an epistemological elephant in the room when talking about poly-space: it is always experienced subjectively. Since it builds on personal experiences, memories, senses, affective capacities and social awareness of the individual and the social surrounding in which the experiencer is located, it is always different. Two people visiting the same site will not experience it in the same way, neither will a person visiting the same site again experience it in exactly the same way as they did before. Therefore, the whole idea of taking poly-space seriously breaks a foundational rule of scientific knowledge - its repeatability.

Moreover, our insights were not gained by knowledge or cognitive work alone but through the entanglements of sensory experiences, affective reactions and intuitive knowledge that sparked a cognitive process. Allowing these sensory elements to play a role in our collaborative sense-making practices has been a form of epistemological critique or a challenge to the status quo of scientific knowledge. As Culhane explains:

Academic conventions reflect this culturally and historically specific approach to knowledge where sights, words, and text are privileged, whereas dynamic interactions among sounds, tastes, odors, touches, senses of place and of belonging and exclusions, and the extrasensory are often ignored or dismissed as irrelevant to social life and the study of knowledge. To take sensory experience, like imagination, as significant in knowledge co-creation constitutes a practice of epistemological and political critique. (Culhane 2017, 11)

It is precisely because of these sensory aspects of knowledge that "one cannot reduce understanding to a method, [...] the fusion at the center of understanding means that we must see knowledge production as a flexible, creatively, historically influenced process" (Cerwonka 2007, 23). Both understanding and knowledge are always partial and situated (Haraway 1991) and to a significant degree also conditioned by our own personal histories which "shape our capacities for affect as well as interpretation of affective experiences" (Sather-Wagstaff 2017, 23). Acknowledging and interpreting these situationalities needs to be at the core of reflexive work around knowledge production, as it allows us to map the boundaries, overlaps and conflicts in and between our cognitive processes.

As we have argued in this chapter, collaborative reflexive work can allow new forms of knowledge to emerge from affective encounters in the field. Poly-space would not have developed as a concept without our team engaging in interpretive reflexivity and 
affective sharing of the inarticulatable. Our embodied experiences, taken individually, seemed initially rather personal and irrelevant to academic knowledge. Yet they made sense when connected with other similar experiences. Only through this merging or integration of diverse experiences and perspectives were we able to produce knowledge that we could not have created as individual ethnographers. We co-constructed this knowledge through our collaborative meaning-making practices. For the researchers, engaging in this type of emotional and intellectual sharing demands profound openness, reflexivity, empathy and, ultimately, courage.

\section{Acknowledgements}

This work was supported by the European Research Council (ERC) under the EU's Horizon 2020 Research and Innovation Programme under Grant 636177 (EUROHERIT). The content of this chapter does not reflect the official opinion of the European Union. Responsibility for the information and views expressed in the chapter lies entirely with the authors.

\section{Notes}

1 Legitimation of European cultural heritage and the dynamics of identity politics in the EU, European Research Council, H2020, 2015-2020.

2 Alcide De Gasperi's House Museum, Italy; Archaeological Park Carnuntum, Austria; Camp Westerbork, The Netherlands; European District of Strasbourg, France; Franz Liszt Academy of Music, Hungary; Great Guild Hall, Estonia; Hambach Castle, Germany; Historic Gdańsk Shipyard, Poland; Mundaneum, Belgium; Robert Schuman's House, France; and Sagres Promontory, Portugal.

\section{Bibliography}

Blumer, H. 1933. Movies and Conduct. New York: Macmillan and Company.

Bourdieu, P., and L. Wacquant. 1992. An Invitation to Reflexive Sociology. Chicago: Chicago University Press.

Boyer D., and G. Marcus. 2015. "Introduction". In Theory Can Be More Than It Used to Be: Learning Anthropology's Method in a Time of Transition, edited by D. Boyer, J. Faubion, and G. Marcus, 1-12. Ithaca, NY: Cornell University Press.

Burgess, R., and A. Murcott. 2014. Developments in Sociology. Hoboken: Taylor and Francis. Büscher, M., and Urry, J. 2009. "Mobile methods and the empirical". European Journal of Social Theory 12 (1), 99-116. https://doi.org/10.1177/1368431008099642

Cerwonka, A. 2007. "Nervous conditions: The stages in interdisciplinary research". In Improvising Theory: Process and Temporality in Ethnographic Fieldwork, edited by A. Cerwonka and L. H. Malkki, 1-40. Chicago: University of Chicago Press.

Cerwonka A., and L. H. Malkki, eds. 2007. Improvising Theory: Process and Temporality in Ethnographic Fieldwork. Chicago: University of Chicago Press.

Chakrabarty, D. 2000. Provincializing Europe: Postcolonial Thought and Historical Difference. Princeton, NJ: Princeton University Press. 
Clifford, J. 1986. "Introduction: Partial truths". In Writing Culture: The Poetics and Politics of Ethnography, edited by J. Clifford and G. Marcus, 1-26. Berkeley: University of California Press.

Clifford, J., and G. Marcus. 1986. Writing Culture: The Poetics and Politics of Ethnography. Berkeley: University of California Press.

Comaroff, J., and J. Comaroff. 1992. Ethnography and the Historical Imagination. Boulder: Westview.

Crang, M., and D. Tolia-Kelly. 2010. "Nation, race, and affect: Senses and sensibilities at National Heritage sites". Environment and Planning A 42 (10): 2315-2331.

Creese, A., A. Bhatt, N. Bhojani, and P. Martin. 2008. "Fieldnotes in team ethnography: Researching complementary schools". Qualitative Research 8 (2): 197-215.

Culhane, D. 2017. "Imagining: An introduction". In A Different Kind of Ethnography: Imaginative Practices and Creative Methodologies, edited by D. Elliott and D. Culhane, 1-21. North York, Ontario, Canada: University of Toronto Press.

Dalsgaard, S., and M. Nielsen. 2013. "Time and the field". Social Analysis 57 (1): 1-19. doi:10.3167/sa.2013.570101

Davies, C. A. 2008. Reflexive Ethnography: A Guide to Researching Selves and Others. 2nd ed. London: Routledge.

Elliott, D., and D. Culhane, eds. 2017. A Different Kind of Ethnography: Imaginative Practices and Creative Methodologies. North York, Ontario, Canada: University of Toronto Press.

Evans-Pritchard, E. E. 1940. The Nuer: A Description of the Modes of Livelihood and Political Institutions of a Nilotic People. Oxford: Clarendon Press.

Falzon, M-A. 2009. Multi-Sited Ethnography; Theory, Praxis and Locality in Contemporary Social Research. Farnham: Ashgate Publishing.

Fenske, M., and Davidovic-Walther, A. 2010. "Exploring ethnological knowledges". Journal of Folklore Research: An International Journal of Folklore and Ethnomusicology 47 (1-2): 1-5. doi:10.2979/JFR.2010.47.1-2.1

Foucault, M. 1997. "Of other spaces: Utopias and heterotopias". In Rethinking Architecture: A Reader in Cultural Theory, edited by N. Leach, 330-336. New York: Routledge.

Franks, D., P. Dale, R. Hindmarsh, C. Fellows, M. Buckridge, and P. Cybinski. 2007. "Interdisciplinary foundations: Reflecting on interdisciplinarity and three decades of teaching and research at Griffith University, Australia". Studies in Higher Education 32: 167-185.

Geertz, C. 1973. The Interpretation of Cultures: Selected Essays. New York: Basic Books.

Haraway, D. J. 1991. "Situated knowledges: The science question in feminism and the privilege of partial perspective". In Simians, Cyborgs and Women: The Reinventions of Nature, by D. Haraway, 183-201. New York: Routledge.

Hazan, H., and E. Hertzog, eds. 2011. Serendipity in Anthropological Research: The Nomadic Turn. Farnham: Ashgate.

Hirsch, M. 2012. The Generation of Postmemory: Writing and Visual Culture after the Holocaust. New York: Columbia University Press.

Hämeenaho, P., and E. Koskinen-Koivisto. 2014. Moniulotteinen etnografia [Multidimensional Ethnography]. Helsinki: Ethnos.

Ingold, T. 2008. "Bindings against boundaries: Entanglements of life in an open world". Environment \& Planning A 40 (8): 1796-1810.

Jarzabkowski, P., R. Bednarek, and L. Cabantous. 2015. "Conducting global team-based ethnography: Methodological challenges and practical methods". Human Relations 68 (1): 3-33.

Katz, J. 2012. "Ethnography's expanding warrants". The Annals of the American Academy of Political and Social Science 642 (1): 258-275. doi:10.1177/0002716212437342 
Kazeem, F. A. 2016. "Time in Yorùbá culture”. Al-Hikmat 36: 27-41.

Lichterman, P. 2015. "Interpretive reflexivity in ethnography”. Ethnography 18 (1): 35-45.

Lähdesmäki, T., and K. Mäkinen. 2019. "The 'European significance' of heritage: Politics of scale in EU heritage policy discourse". In Politics of Scale. New Directions in Critical Heritage Studies, edited by T. Lähdesmäki, S. Thomas, and Y. Zhu, 36-49. New York: Berghahn Books.

Lähdesmäki, T., L. Passerini, S. Kaasik-Krogerus, and I. van Huis, eds. 2019. Dissonant Heritages and Memories in Contemporary Europe. New York: Palgrave Macmillan.

Lähdesmäki, T., V. L. A. Čeginskas, S. Kaasik-Krogerus, K. Mäkinen, and J. Turunen. 2020. Creating and Governing Cultural Heritage in the European Union: The European Heritage Label. London: Routledge.

Macdonald, S. 2013. Memorylands: Heritage and Identity in Europe Today. New York: Routledge.

Malinowski, B. 1922/1972. Argonauts of the Western Pacific: An Account of Native Enterprise and Adventure in the Archipelagoes of Melanesian New Guinea. 8th edn. London: Routledge and Kegan Paul.

Malkki, L. 2007. "Tradition and improvisation in ethnographic field research". In Improvising Theory: Process and Temporality in Ethnographic Fieldwork, edited by A. Cerwonka and L. H. Malkki, 162-188. Chicago: University of Chicago Press.

Marcus, G. E. 1995. "Ethnography in/of the world system: The emergence of multi-sited ethnography”. Annual Review of Anthropology 24: 95-117.

Massey, D. 2005. For Space. London: Sage.

Park, R. E., Burgess, E. W., and McKenzie, R. D. 1926. City. Chicago: Chicago University Press.

Puddephatt, A., W. Shaffir, and S. Kleinknecht. 2009. Ethnographies Revisited: Constructing Theory in the Field. Milton Park: Routledge.

Rivoal, I., and N. B. Salazar. 2013. "Contemporary ethnographic practice and the value of serendipity”. Social Anthropology/Anthropologie Sociale 21 (2): 178-185.

Rothberg, M. 2009. Multidirectional Memory: Remembering the Holocaust in the Age of Decolonization. Stanford, California: Stanford University Press.

Sather-Wagstaff, J. 2017. "Making polysense of the world: affect, memory and heritage". In Heritage, Affect and Emotion. Politics, Practices and Infrastructures, edited by D.P. Tolia-Kelly, E. Waterton, and S. Watson, 12-29. Abingdon: Routledge.

Spiller K., K. Ball, E. Daniel, S. Dibb, M. Meadows, and A. Canhoto. 2015. "Carnivalesque collaborations: Reflections on 'doing' multi-disciplinary research". Qualitative Research 15 (5): 551-567.

Stocking, G. W. ed. 1991. Colonial Situations: Essays on the Contextualization of Ethnographic Knowledge. Madison, Wis.: University of Wisconsin Press.

Tolia-Kelly, D. P. 2006. "Affect - an ethnocentric encounter? Exploring the 'universalist' imperative of emotional/affectual geographies". Area 38 (2): 213-217.

Tolia-Kelly, D. P., E. Waterton, and S. Watson 2017. "Introduction: Heritage, affect and emotion". In Heritage, Affect and Emotion. Politics, Practices and Infrastructures, edited by D. P. Tolia-Kelly, E. Waterton and S. Watson, 1-11. New York: Routledge.

Turner, V. 1974. "Liminal to liminoid, in play, flow and ritual: An essay in comparative symbology". Rice University Studies 60 (3): 53-92.

Turunen, J. 2019. "A geography of coloniality: Re-narrating European integration". In Dissonant Heritages and Memories in Contemporary Europe, edited by T. Lähdesmäki, L. Passerini, S. Kaasik-Krogerus, and I. van Huis, 185-214. New York: Palgrave Macmillan. van Maanen, J. 2011. Tales of the Field: On Writing Ethnography. 2nd edn. Chicago: University of Chicago Press. 
20 J. Turunen et al.

Wasser, J. D., and L. Bresler. 1996. "Working in the interpretive zone: Conceptualizing collaboration in qualitative research teams". Educational Researcher 25 (5): 5-15.

Waterton, E. 2014. "A more-than-representational understanding of heritage? The 'past' and politics of affect”. Geography Compass 8 (11): 823-833. 